\title{
Química Run: Uma Ferramenta Lúdico-Educativa no Ensino de Química
}

\author{
Gabriel F. Alves, Emerson V. Souza, Pedro M. de Sousa \\ ${ }^{1}$ Instituto de Ciências Exatas e Tecnológicas - Universidade Federal \\ de Viçosa campus Rio Paranaíba (UFV-CRP) \\ Rodovia MG-230, Km 07, Campus Universitário - CEP 38810-000 - \\ Rio Paranaíba - Minas Gerais - Brasil \\ \{gaferreira08, evsemerson1, profpedromoises\}@gmail.com
}

\begin{abstract}
For students who attend high school, chemistry discipline is generally seen as a difficult and often incomprehensible matter. The use of digital games can facilitate the absorption of concepts seen in the room to be something fun and interesting. This paper presents information on "Quimica Run", a game that exposes information about the elements of the families of the periodic table.

Resumo. Para os alunos que cursam o Ensino Médio, a disciplina Química geralmente é vista como uma matéria difícil e, muitas das vezes, incompreensível. $O$ uso de jogos digitais pode facilitar a absorção de conceitos vistos dentro de sala por ser algo divertido e interessante. Este trabalho apresenta informações sobre "Química Run”, um jogo que expõe dados sobre os elementos das famílias da tabela periódica.
\end{abstract}

\section{Introdução}

Atualmente, os jogos digitais se destacam por possuírem a maior indústria de entretenimento do mundo. Neste contexto, alguns projetos acabam por tomar proporções gigantes, trabalhando com tecnologias de última geração e com investimentos que podem atingir a casa dos milhões de dólares [Neves et al. 2014]

Os jogos digitais podem ser definidos como ambientes atraentes e interativos que capturam a atenção do jogador ao oferecer desafios que exigem níveis crescentes de destreza e habilidades [Balasubramanian and Wilson 2006]. Eles podem se tornar ferramentas eficientes para o aprendizado, já que eles buscam a atenção do jogador, motivando e exercitando funções mentais e intelectuais [Martins and Silva 2015].

O jogo digital "é um recurso tecnológico lúdico, que agrega fatores como: diversão, prazer, habilidades e conhecimento"[Sousa et al. 2011]. Partindo desse pressuposto, se direcionarmos todos os recursos que o mesmo oferece, aplicando as técnicas e o conhecimento na área de Química, pode-se alcançar o público jovem e adulto, de forma que o interesse seja despertado entre os citados.

Um dos desafios a se desenvolver uma ferramenta desse estilo, é que deve haver equilíbrio no lado lúdico e no lado educativo desta ferramenta; se o lúdico prevalecer ele será apenas mais um jogo digital, feito para o entretenimento. Porém, se o lado educativo for maior, será outra ferramenta educativa. É importante que as duas estejam equilibradas para que o aluno se sinta atraído pelo jogo, mas não desmotivado pelas dificuldades que a disciplina pode induzir. 
Para alunos que estão tendo contato com a disciplina Química pela primeira vez, é possível que encontrem dificuldades em assimilar todos os elementos da tabela periódica a seus nomes, número atômico, propriedades e afins. Ao envolver química com jogos digitais, este trabalho visa aprofundar os conceitos já vistos em sala de aula sobre os elementos da tabela.

O jogo em questão tenta passar conceitos básicos de cada elemento da tabela periódica, buscando relacionar o raciocínio do aluno-jogador com o conhecimento básico mostrado em sala de aula de uma forma divertida e interessante.

\section{Jogos Digitais Educacionais}

Os jogos digitais podem ser definidos como ambientes atraentes e interativos que capturam a atenção do jogador ao oferecer desafios que exigem níveis crescentes de destreza e habilidades [Balasubramanian and Wilson 2006]. Eles podem se tornar ferramentas eficientes para o aprendizado, já que eles buscam a atenção do jogador, motivando e exercitando funções mentais e intelectuais [Martins and Silva 2015].

Savi e Ulbricht (2008) dizem que, para que jogos possam ser utilizados como instrumentos educacionais, eles devem conter algumas características vinculadas à aprendizagem. Os softwares educacionais devem possuir objetivos pedagógicos e sua utilização deve estar inserida em um contexto e em uma situação de ensino baseados em uma metodologia que oriente o processo através da interação, da motivação e da descoberta, facilitando a aprendizagem de um conteúdo [Prieto et al. 2005].

Santana et al. (2015) afirmaram que os jogos, quando utilizados no contexto escolar, podem ser considerados como algo que levam os alunos a criar e exercitar sua imaginação, devendo também ser considerado um auxílio no desenvolvimento cognitivo.

Porém existem alguns desafios quando se trata de trazer uma ferramenta lúdica como essa para o ambiente educacional. Santana et al. (2005) dizem que pode ser complicado encarar jogos como uma atividade séria e que algumas pessoas relacionam os mesmos com violência, já que alguns jogos trazem cenas de brigas e o uso de armas. Cenas violentas sempre existiram em nossa sociedade, como em filmes e novelas e é importante evidenciar que, embora existam games violentos, eles representam apenas uma parte do todo nessa mídia.

\section{Trabalhos Relacionados}

Quando se trata da Realidade Virtual aplicada ao ensino de alguma disciplina, alguns trabalhos são encontrados. O jogo elaborado por Silveira (2016) trabalha o ensino da tabela periódica da seguinte forma: o jogador controla um personagem que anda sobre um chão com a imagem da tabela periódica, podendo selecionar determinado elemento apenas posicionando o personagem em cima do mesmo. Ao fazer isso, são exibidas informações sobre aquele elemento, como número atômico, massa, propriedades, entre outros. Ao efetuar determinadas tarefas, o jogador ganha créditos que podem ser gastos em uma espécie de "supermercado", onde ele pode comprar itens que serão "decompostos"em vários elementos químicos que fazem parte da sua composição. Depois de decompostos, o aluno visualiza as informações citadas anteriormente dos elementos encontrados, adquirindo conhecimentos específicos dos mesmos. 
V Congresso Brasileiro de Informática na Educação (CBIE 2016)

Anais dos Workshops do V Congresso Brasileiro de Informática na Educação (CBIE 2016)

O trabalho Aventuras no Mundo da Tabela Periódica se relaciona em vários aspectos com o trabalho desta pesquisa, pois se trata de um jogo em que o aluno-jogador interage com elementos químicos da tabela periódica para aprender curiosidades e propriedades dele.

O jogo desenvolvido por Souza et al. (2016) é voltado para o contexto da química ambiental, sendo a personagem principal uma maga ambientalista que busca corrigir várias atividades humanas que acabaram agravando a poluição do ambiente, devido o uso demasiado de produtos químicos. A personagem tem que conversar com outros personagens espalhados por um ambiente virtual poluído e responder algumas perguntas. Quando a personagem principal acerta uma pergunta, o nível de poluição do cenário diminui, até que o ambiente se torne totalmente limpo. Pelo lado contrário, quando a personagem erra uma pergunta, o local se torna mais poluído. O jogo é concluído quando todas as perguntas são respondidas corretamente e o nível de poluição ambiental se torna mínimo.

O trabalho citado acima e o abordado nestaa pesquisa possuem uma abordagem semelhante, tratando do desenvolvimento de um jogo educacional na área de química, divergindo nos objetivos, sendo que o trabalho relacionado lida com a relação da química com o meio ambiente, enquanto o Química Run usa da tabela periódica para explicar as propriedades dos seus elementos.

\section{Metodologia}

A proposta deste trabalho é a criação de um jogo educativo usando conceitos de Realidade Virtual aplicado no ensino da disciplina Química. Seu desenvolvimento foi baseado no Processo Ágil de Desenvolvimento de Sistemas de Realidade Virtual (SRV) definido por Mattioli et al. (2009) e foi desenvolvido seguindo o fato dele ser adequado aos projetos de RV.

O processo em questão é dividido em cinco fases, como mostra a Figura 1.

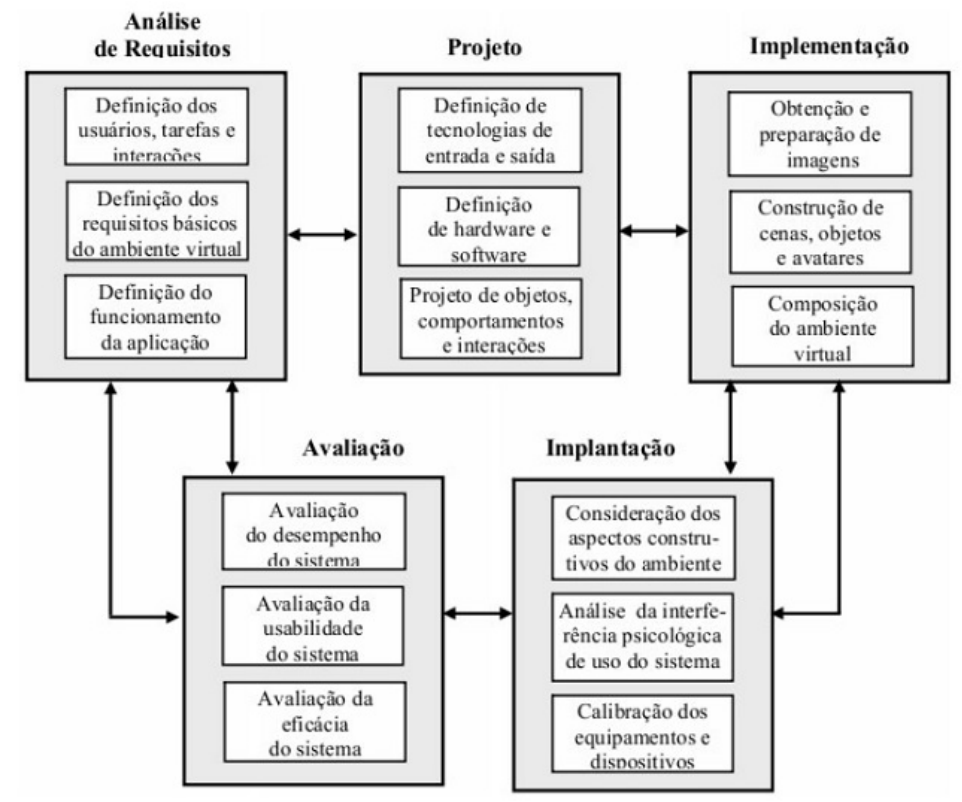

Figura 1. As fases do processo ágil de desenvolvimento 
V Congresso Brasileiro de Informática na Educação (CBIE 2016)

Anais dos Workshops do V Congresso Brasileiro de Informática na Educação (CBIE 2016)

A divisão das tarefas executadas é de total importância, visando que um software como esse, além de todos os aspectos que qualquer outro software teria, também tem grande preocupação com a parte visual.

\subsection{Análise de Requisitos}

Nesta fase definimos particularidades do jogo, como quem é o usuário, o que o jogo deverá fazer, como o usuário irá interagir com os elementos do game, como ele é ambientado e como ele funciona. Esta é uma fase de grande importância, sendo que a interatividade entre o aluno e o sistema é o elemento de papel fundamental na determinação da usabilidade do software [Mattioli et al. 2009].

Pelas definições feitas nesta etapa, o aluno-jogador controla um personagem que está correndo pelo cenário e deve coletar os elementos referentes àquela família da tabela em que ele está. A interação, feita através das teclas up e down do teclado, faz com que o personagem pule e abaixe para desviar de obstáculos presentes no ambiente e selecione os elementos que deve coletar.

\subsection{Projeto}

Aqui, ferramentas importantes para o desenvolvimento foram definidas: tecnologias de entrada (mouse, teclado) e saída (monitor, caixas de som), o comportamento e interações com os objetos e também requisitos mínimos da máquina em que o software estará executado.

\subsection{Implementação}

A obtenção, construção e composição de todo o software foi tratada de forma a simplificar a adaptação do aluno com o jogo. As imagens são bem intuitivas, exibindo os elementos com seus símbolos neles, barreiras a serem ultrapassadas e o avatar carismático, já conhecido por muitos. Todo o jogo foi construído utilizando a engine Unity $3 \mathrm{D}$ e, tratando-se dos scripts, as linguagens utilizadas para a implementação foram JavaScript e C\#. A Figura 2 exemplifica como é a construção do ambiente virtual na Unity 3D.

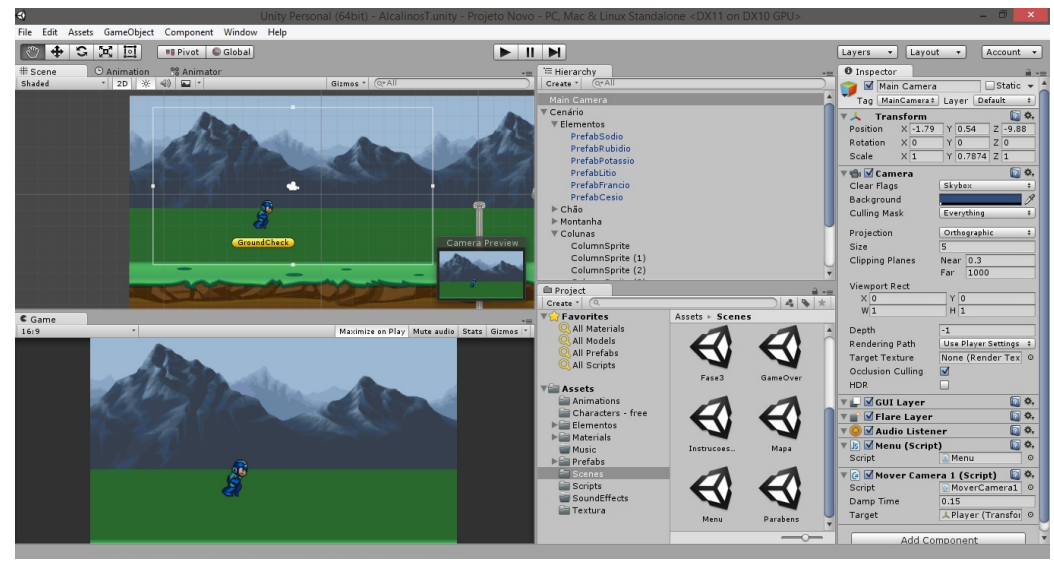

Figura 2. Construção do Ambiente Virtual na Unity 3D 
V Congresso Brasileiro de Informática na Educação (CBIE 2016)

Anais dos Workshops do V Congresso Brasileiro de Informática na Educação (CBIE 2016)

\subsection{Implantação}

Seguindo o modelo da Metodologia, a Implantação se trata de aplicar o jogo devidamente desenvolvido em um ambiente onde ele possa ser aplicado para utilização. Esta atividade demanda da existência de laboratórios em escolas para que os alunos possam usufruir do jogo e o professor possa testar se ela está realmente surtindo efeito como uma ferramenta lúdico-educativa.

\subsection{Avaliação}

Ao falar da Avaliação, temos em mente avaliar a usabilidade do sistema, sendo que o mesmo deverá poder ser executado em vários modelos de máquinas, já que as escolas muitas das vezes não contam com um laboratório fortemente equipado.

Aqui mede-se a eficiência da ferramenta, o tempo de resposta do sistema quando um comando é executado, se o propósito foi cumprido e o que é necessário mudar. Os dados colhidos estão presentes na sessão de Resultados.

\section{Funcionamento do Sistema}

Antes de iniciar o jogo, a tela de Menu é exibida, como mostra a Figura 3. Nela, três botões estão disponíveis para o usuário selecionar, sendo eles:

- Jogar, onde o jogador é levado diretamente para o jogo.

- Créditos, onde são mostradas informações sobre os desenvolvedores e sobre o jogo.

- Sair, onde o jogador encerra o jogo.

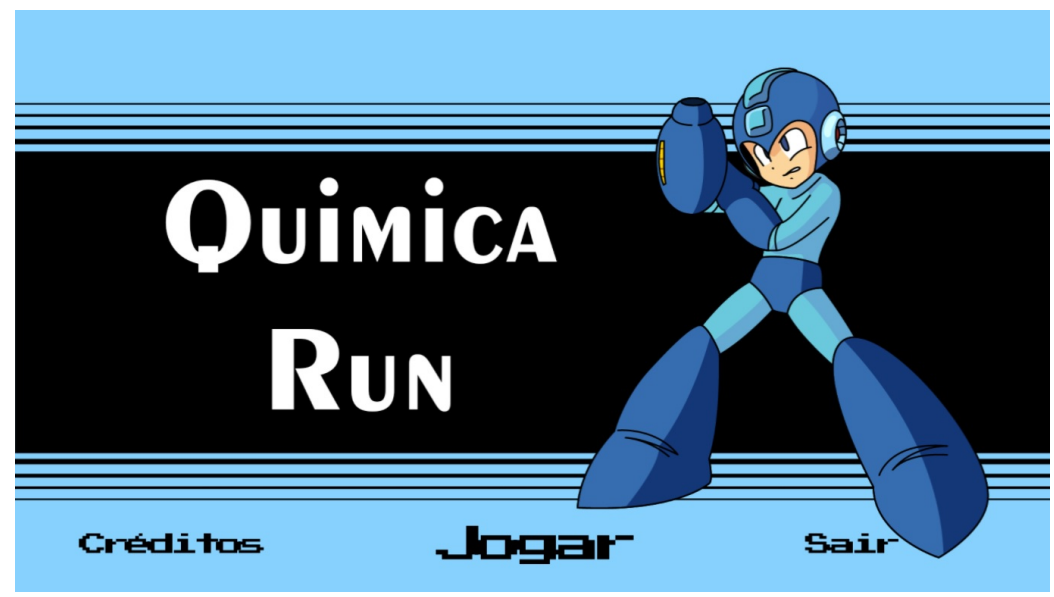

Figura 3. Tela Inicial

Ao clicar no botão "Jogar", o aluno-jogador é direcionado a uma tela onde é exibida a Tabela Periódica modificada para se que assemelhe com um mapa, como mostra a Figura 4. A divisão desse mapa é realizada de acordo com algumas classificações presentes na Tabela Periódica, sendo elas: Metais Alcalinos, Metais Alcalinos Terrosos, Gases Nobres, Metais Lantanídeos, Metais Actinídeos, Ametais e Outros Metais. Cada uma dessas classificações é representada como um continente do universo do jogo e cada continente representa uma fase jogável. 
V Congresso Brasileiro de Informática na Educação (CBIE 2016)

Anais dos Workshops do V Congresso Brasileiro de Informática na Educação (CBIE 2016)

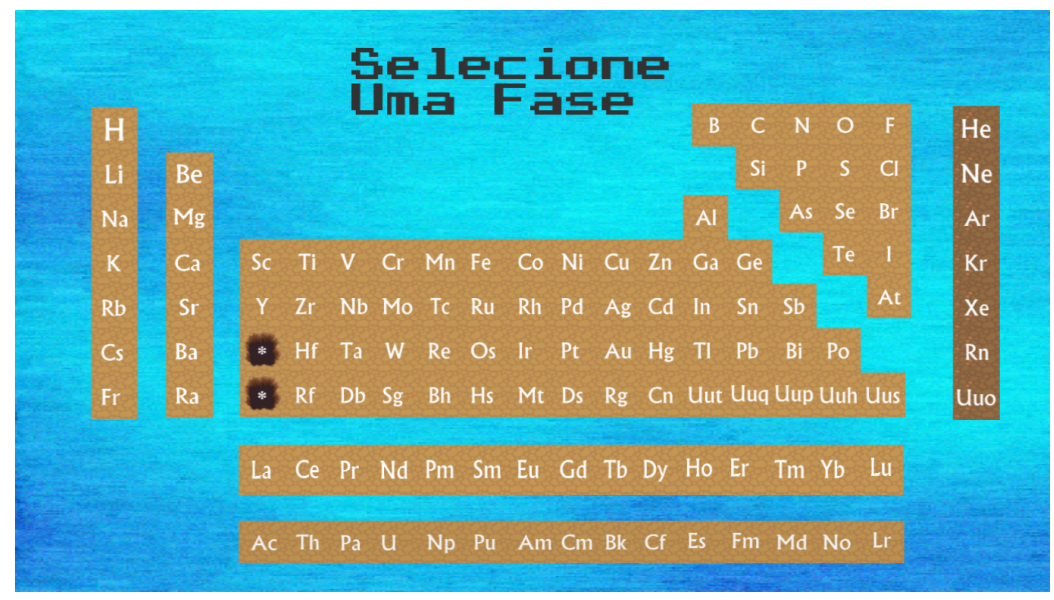

Figura 4. Mapa

No início do jogo, somente a fase relativa aos Metais Alcalinos estará disponível para ser selecionada e, ao clicar nela, é exibida uma tela com as instruções que devem ser seguidas para alcançar o objetivo daquela fase. Como objetivos, temos: quais elementos o personagem deve coletar e como desviar de obstáculos presentes no cenário. A Figura 5 exemplifica como são exibidas as instruções dentro do jogo.

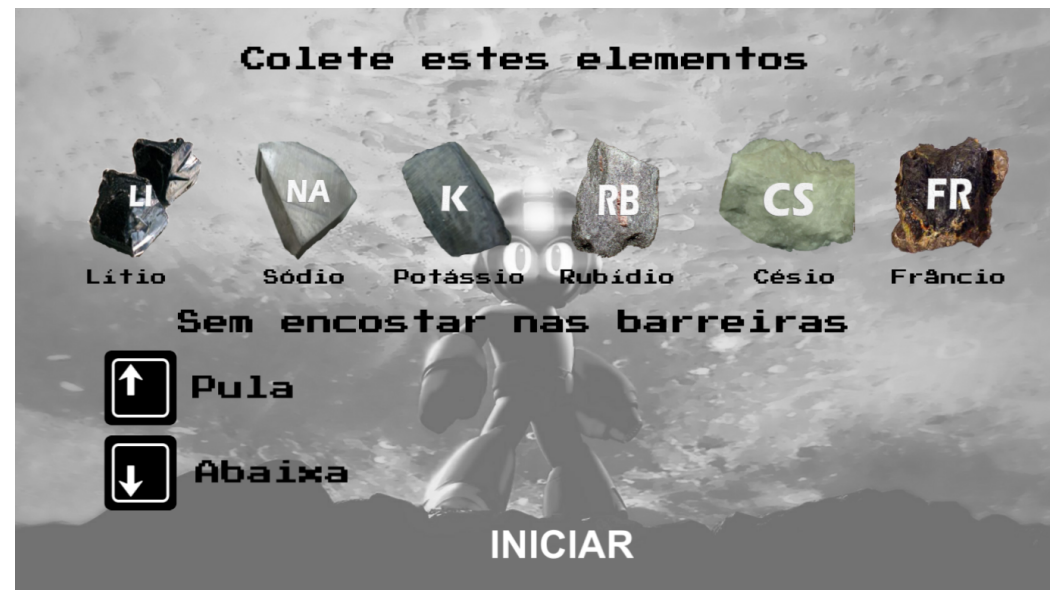

Figura 5. Instruções da Primeira Fase

Ao clicar em "Iniciar", o jogador é levado para a primeira fase do jogo. O objetivo de cada fase é coletar todos os elementos referentes àquela família em que ele se encontra, sem coletar elementos não pertencentes a ela ou esbarrar nos obstáculos. A Figura 6 mostra como a fase referente aos Metais Alcalinos está ambientada.

Quando o personagem chega ao final daquela fase com todos os elementos coletados corretamente, ele poderá seguir para a próxima fase. Caso ele tenha coletado algum elemento que não pertença a àquela família, uma tela é mostrada informando ao jogador que ele deverá coletar apenas aqueles elementos mostrados no início da fase. Por último, caso o personagem esbarre em algum dos obstáculos, é exibida a tela de Game Over e ele é forçado a começar aquela fase do início, como exibe a Figura 7. 
V Congresso Brasileiro de Informática na Educação (CBIE 2016)

Anais dos Workshops do V Congresso Brasileiro de Informática na Educação (CBIE 2016)

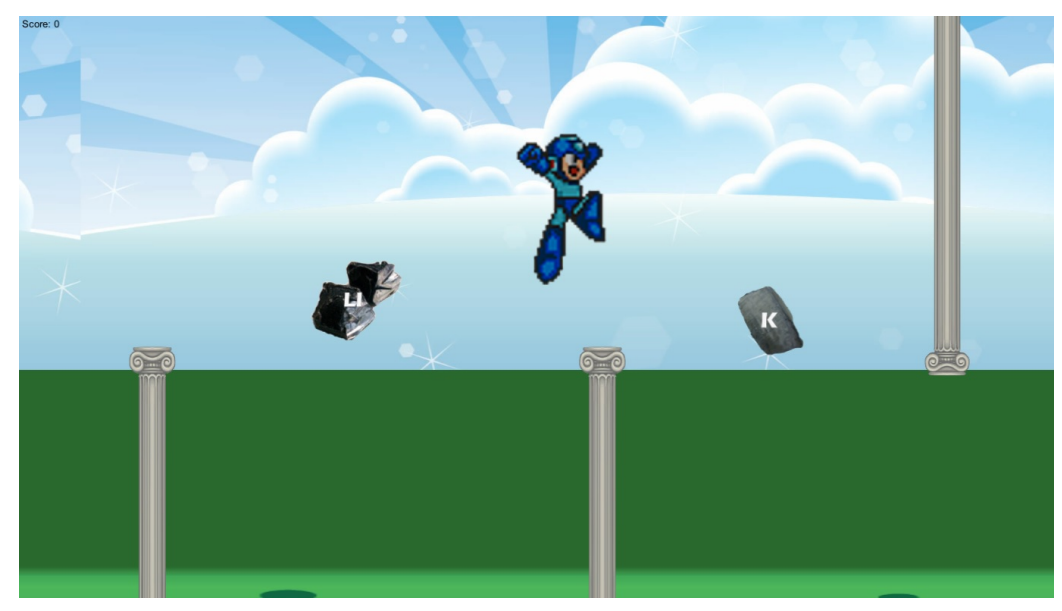

Figura 6. Fase 1: Metais Alcalinos

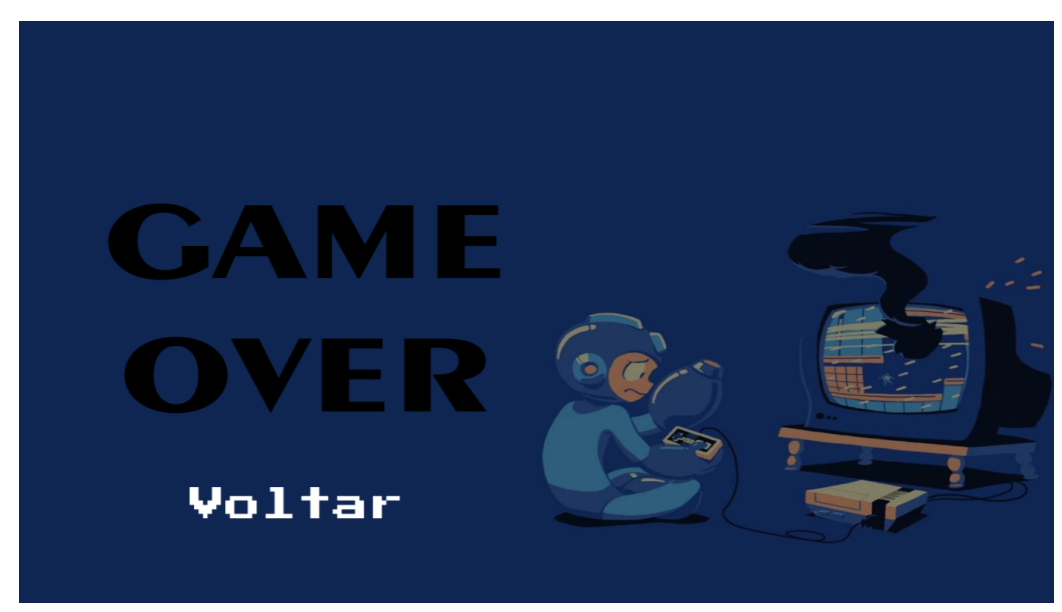

Figura 7. Game Over

Ao finalizar corretamente uma fase, uma tela é exibida com informações sobre a família que o jogador concluiu, como: nome da família, nome dos elementos pertencentes à ela, número atômico dos elementos e algumas propriedades dos mesmos. O intuito do jogo é o aprendizado por exposição, onde o aluno, ao concluir o objetivo, recebe as informações que coletou.

\section{Resultados}

O jogo foi apresentado em uma Mostra de Jogos organizada no Pavilhão de Aulas da Universidade Federal de Viçosa campus Rio Paranaíba, onde vários alunos jogaram o jogo Química Run. Desses alunos, vinte e cindo deles responderam um questionário com algumas perguntas relacionadas ao jogo, como "O jogo evolui em um ritmo adequado e não fica monótono?", "O jogo é fácil de jogar e entender?"e "Me senti estimulado a aprender com o jogo?". As Figuras 8, 9 e 10 mostram os gráficos com a porcentagem dessas respostas, sendo as notas atribuídas de 1 a 5. 
V Congresso Brasileiro de Informática na Educação (CBIE 2016)

Anais dos Workshops do V Congresso Brasileiro de Informática na Educação (CBIE 2016)

O jogo evolui em um ritmo adequado e não fica monótono?

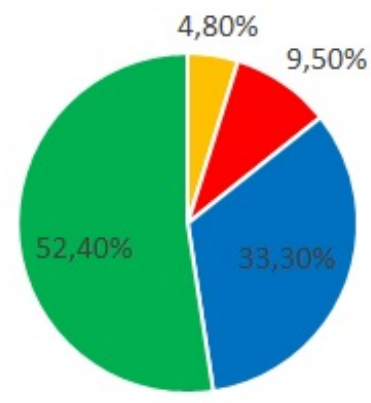

$=1=2 \cdot 3 \cdot 4=5$

Figura 8. 0 jogo evolui em um ritmo adequado e não fica monótono?

O jogo é fácil de jogar e entender?

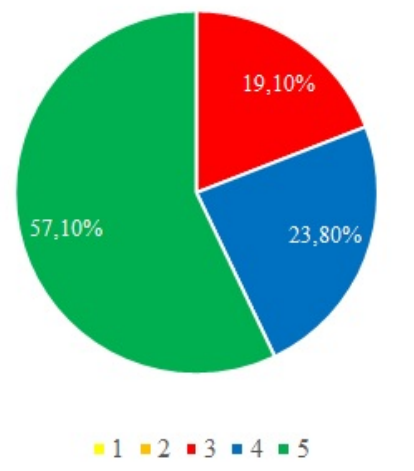

Figura 9. 0 jogo é fácil de jogar e entender?

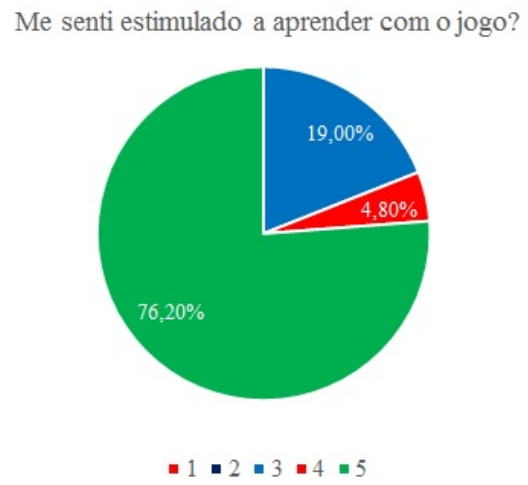

Figura 10. Me senti estimulado a aprender com o jogo? 
V Congresso Brasileiro de Informática na Educação (CBIE 2016)

Anais dos Workshops do V Congresso Brasileiro de Informática na Educação (CBIE 2016)

\section{Conclusão}

Com base nos resultados obtidos após a aplicação do jogo e da análise dos resultados, podemos perceber que ele foi muito bem recebido pelos jogadores. Ainda assim há a necessidade de melhorar alguns aspectos que possam ajudar o aluno a absorver melhor o conteúdo da disciplina.

O uso de jogos digitais no ensino-aprendizagem de disciplinas ainda no ensino fundamental e médio pode trazer melhorias para o aprendizado dos alunos, seja qual for a disciplina em questão. É necessário o cuidado por parte do desenvolvedor ao desenvolver uma ferramenta desse tipo, buscando sempre o equilíbrio entre o lúdico e o educacional.

É importante ressaltar também que a ferramenta é interessante como forma de auxílio no ensino, e não como algo que possa substituir o professor; o propósito é que a ferramenta seja utilizada como meio de revisar o que já foi visto dentro de sala previamente, ajudando na fixação de conceitos passados pelo professor.

\section{Referências}

Azevedo, E. and Conci, A. (2003). Computação gráfica: teoria e prática. Elsevier.

Balasubramanian, N. and Wilson, B. G. (2006). Games and simulations. ForeSITE, 2005:2.

Braga, M. (2001). Realidade virtual e educação. Revista de biologia e ciências da terra, 1(1):1-13.

de Paula Souza, T. V., de Paula Souza, É. V., da Silva, T. G. N., de Medeiros Silva, D., and Ribeiro, M. E. N. P. (2016). Proposta educativa utilizando o jogo rpg maker: Estratégia de conscientização e de aprendizagem da química ambiental. HOLOS, 8:98-112.

Kilner, C. and Tori, R. (2004). Realidade Virtual: conceitos e tendências. Editora Mania de Livro.

Manssour, I. H. and Cohen, M. (2006). Introdução à computação gráfica. RITA, 13(2):4368.

Martins, R. T. and Silva, G. A. (2015). Realidade virtual aplicada ao ensino aprendizagem de inglês.

Mattioli, F. E., Lamounier Jr, E. A., Cardoso, A., Alves, N. M., and Muniz, M. (2009). Uma proposta para o desenvolvimento ágil de ambientes virtuais. SBC. Anais do WRVA.

Neves, A. M. d. M. et al. (2014). Utilização da metodologia design card game na configuração de mecânicas para jogos digitais.

Prieto, L. M., Trevisan, M. d. C. B., Danezi, M. I., and Falkembach, G. M. (2005). Uso das tecnologias digitais em atividades didáticas nas séries iniciais. Renote, 3(1).

Santana, M. G., Silva, L. F., Dantas, M. V., Santos, C. A. N., and Coelho, P. M. F. (2015). Jogos digitais: Brincadeira ou auxílio pedagógico? In Anais do Congresso de Inovação Pedagógica em Arapiraca, volume 1.

Savi, R. and Ulbricht, V. R. (2008). Jogos digitais educacionais: benefícios e desafios. RENOTE, 6(1). 
V Congresso Brasileiro de Informática na Educação (CBIE 2016)

Anais dos Workshops do V Congresso Brasileiro de Informática na Educação (CBIE 2016)

Silveira, A. C. d. (2016). Aventuras no mundo da tabela periódica: criação de uma aplicação pedagógica para o ensino de química.

Sousa, R. P. d., Moita, F. d., Carvalho, A. B. G., et al. (2011). Tecnologias digitais na educação. 